\title{
Community-Based Screening for Pre-hypertension among Military Active Duty Personnel
}

\author{
Fayssal M. Farahat ${ }^{*}$, Fathi A. Saleem ${ }^{\dagger}$
}

\begin{abstract}
Background: The majority of hypertension cases are asymptomatic and, therefore, goes unrecognized and untreated, leading to a high risk of coronary artery diseases, heart failure, renal failure, and cardiovascular diseases. Objective: The purpose of this study was to determine the prevalence of both pre-hypertension and hypertension and risk factors associated with newly diagnosed Saudi military active duty service personnel. Methods: Community-based screening of 1238 Saudi military active duty service personnel was conducted during the period September - December 2007 at six randomly selected out of a total of 15 military units of Taif region, Western of Saudi Arabia. Screening tools included self-administrated questionnaire, general physical examination, anthropometric measurements, and assessment of blood pressure. Results: All participants were Saudi males. Their age ranged from 19-56 years old with mean $\pm S D$ of $37.2 \pm 7.02$. By applying the Joint National Committee on prevention, detection, evaluation, and treatment of high hypertension (JNC-7) criteria, 214 (17.3\%) were considered pre-hypertensive. Multivariate logistic regression analysis showed that obesity as measured by body mass index $(\mathrm{OR}=2.71, \mathrm{Cl}$ : 1.39-5.28), positive family history ( $\mathrm{OR}=1.46, \mathrm{Cl}: 1.03-2.06)$, ever smoking $(\mathrm{OR}=1.45, \mathrm{Cl}: 1.05-2.02)$, and increased waist circumference $(\mathrm{OR}=1.04, \mathrm{Cl}: 1.02-1.06)$ were the significant predictors of workplace newly diagnosed hypertension among military active duty personnel. Conclusion: Pre-hypertension is a common hidden problem and it predicts the development of frank hypertension. Findings of the current study support the recommendation of lifestyle modification for pre-hypertension patients. However, further prospective studied are required to determine the role of pharmacotherapy in pre-hypertension.
\end{abstract}

Key words: screening, prehypertension, military

\section{INTRODUCTION}

Hypertension, a major public health problem world wide, is associated with high morbidity and mortality rates ${ }^{(1)}$. The majority of cases are asymptomatic and, therefore, go unrecognized and untreated, leading to a high risk of coronary artery disease, heart failure, renal failure and cerebrovascular diseases ${ }^{(2-4)}$. Studies on the prevalence of hypertension in Saudi Arabia are variant, ranging from $10-$
$30 \%(5-7)$. This high prevalence rate in the general population is attributed to several cultural and lifestyle factors that had been dramatically changed during the past few years ${ }^{(5,8)}$.

Military personnel are occupational group with special characteristics. Being away from their families for long periods, frequent movement away from their base for military maneuvers, 
punctual attendance at their place of work, and work overload contribute significantly to job strain and consequently stress-related diseases $^{(2,3,9)}$. Studies that have been conducted to assess the prevalence of hypertension (and other chronic diseases) and associated risk factors among this special occupational group are very lacking worldwide(1).

\section{Current blood pressure (BP)} classification is based on the recent recommendations of Joint National Committee on prevention, detection, evaluation, and treatment of high blood pressure (JNC-7) and the 2003 European Society of HypertensionEuropean Society of Cardiology Guidelines for the management of Arterial Hypertension²,10. The JNC-7 introduced a new concept, prehypertension, for systolic blood pressure (SBP) levels of $120-139$ and diastolic BP levels of $80-89 \mathrm{mmHg}^{(1,2)}$ and recommended screening programs for early detection of prehypertensive cases and health-promoting lifestyle modifications for these individuals(1). The purpose of this study was to determine the prevalence of both pre-hypertension and hypertension and risk factors associated with newly diagnosed Saudi military active duty service personnel.

\section{MATERIAL AND METHODS}

Community-based screening of 1238 Saudi military active duty service personnel was conducted during the period from September - December 2007 at six randomly selected out of a total of 15 military units at Taif region, western of Saudi Arabia. Approval of the administration of Taif Armed Forces Hospitals was obtained to conduct the study. These hospitals are serving military personnel and their dependents at Taif region. The study was conducted during regular working hours (between 8:00 am - 4:00 pm) at the clinic of each military unit.

All military active duty service personnel (conscripts) at the selected units were invited to voluntary participate in this screening survey. A response rate of approximately $90 \%$ was obtained. Screening tools included self-administered questionnaire, 
general physical examination, anthropometric measurements (weight, height, and abdominal circumference), and assessment of blood pressure. The questionnaire consisted of personal history (age, marital status, and educational level), history of morbidities (diabetes mellitus and hypertension), family history of chronic conditions (e.g., diabetes, hypertension, and heart disease), and personal smoking history. Anthropometric measurements were obtained at initial contact with each participant. A flexible, nonstretchable plastic measuring tape was used to determine waist circumference. Measurement was made at the mid-point between the costal margin and superior iliac crest to the nearest centimeter. According to National Institute of Health guidelines, male Waist Circumference (WC) $>102 \mathrm{~cm}$ is considered abnormal. Height and weight were measured with Healthometer scales manufactured by Continental Scale Corporation, Bridgeview, Illinois, USA. The scales were calibrated daily, before the start of the working day. Height was measured to the nearest 0.5 centimeter; barefoot and without any headgear. Body weight was measured with a $0.1-\mathrm{kgm}$ precision in light clothing. Body mass index was calculated by dividing weight in kilograms by the square of height in meters. Participants were classified according to World Health Organization into the following categories: underweight $\left(<18.5 \mathrm{~kg} / \mathrm{m}^{2}\right)$; normal (18.5-24.9 kg/m²); overweight $\left(25-29.9 \mathrm{~kg} / \mathrm{m}^{2}\right)$; obesity $\left(\geq 30 \mathrm{~kg} / \mathrm{m}^{2}\right)$. After each participant had seated for 5-10 minutes, blood pressure was measured twice to the nearest $2 \mathrm{mmHg}$ with the participant setting and left arm resting on the table using a standard mercury sphygmomanometer (Diplomat Presameter 660-360 manufactured by Riester $\mathrm{GMBH}$, Germany). The average of the two measurements was used for all analyses. Diastolic blood pressure (DBP) was recorded at the $5^{\text {th }}$ korotkoff sound. Hypertension was defined as systolic blood pressure (SBP) $\geq 140$ $\mathrm{mmHg}$ and/or DBP $\geq 90 \mathrm{mmHg}$. Glucomtere devices were used to measure random serum blood glucose level (RBG) of each participant. Individuals with self-reported history of 
diabetes, with anti-diabetic medication and those with RBG exceeding $199 \mathrm{mg} / \mathrm{dl}$ were considered diabetic.

In order to study risk factors associated with pre-hypertension as well as hypertension, a nested case-control study was adopted, where those with SBP $\geq 140 \mathrm{mmHg}$ and/or DBP $\geq 90 \mathrm{mmHg}$ were considered as hypertensives, those with SBP of $120-139$ and/or DBP levels of $80-89 \mathrm{mmHg}$ as prehypertensives, while others were treated as controls.

\section{Statistical Analysis}

Data were entered into the statistical software program, Epi Info version 3.3, released by Centers for Disease Control and Prevention (CDC), Atlanta, Georgia, in October 2004. Hypertension and prehypertension were treated separately as dependent variables in both univariate and logistic regression analysis. Age, history and duration of smoking, family history of hypertension, Body Mass Index, waist circumference, and diabetes mellitus were treated as independent categorical variables.
Univariate data analysis was performed and expressed as crude odds ratios (ORs) and their confidence intervals $(95 \% \mathrm{Cl})$. Multiple associations were evaluated in multiple logistic regression model based on the backward stepwise selection, where significant variables from the univariate analysis were included. This procedure allowed the estimation of the strength of the association between each independent variable while taking into account the potential confounding effects of the other independent variables. The covariates were removed from the model if the likelihood ratio statistic based on the maximum likelihood estimates had a probability of $>0.10$. Each category of the predictor variables was contrasted with the initial category (reference category). The adjusted measure of association between risk factors and hypertension was expressed as the odds ratio (OR) with 95\% Confidence Interval $(95 \% \mathrm{Cl})$. Adjusted or crude ORs with $95 \% \mathrm{Cl}$ that did not include 1.0 were considered significant. 


\section{RESULTS}

All participants were Saudi males. Their age ranged from 19 - 56 years old with mean $\pm S D$ of $37.2 \pm 7.02$ years. Most of them were married (87.2\%) and only $6.4 \%$ of participants have university education. Approximately, half of the participants ever smoked $(48.5 \%)$ with mean $( \pm S D)$ duration of smoking of 10.97 years $( \pm 6.61)$. Obesity in the current study was measured using Body Mass Index and abdominal circumference. $\mathrm{BMI}$ revealed that $38 \%$ of participants were overweight, $28.8 \%$ obese, and $7.5 \%$ underweight. However, $25.5 \%$ have abdominal circumference more than $102 \mathrm{~cm}$ (Table 1).

By applying the NJC-7 criteria, 214 (17.3\%) were considered pre-hypertensive (Table 2). On the other hand, 217 active duty participants (18.6\%) were newly diagnosed with high blood pressure (they neither have past history of hypertension nor take any medication for high blood pressure). Among those who reported past history of hypertension $(n=70), 71.4 \%$ were controlled (either normal or pre-hypertension) compared to $28.6 \%$ with uncontrolled high blood pressure (Table 2). High systolic and diastolic blood pressures were reported in $5.9 \%$ of all participants, high diastolic in $11.8 \%$ and high systolic in only $1.5 \%$.

Univariate logistic regression analysis was performed to determine risk factors among newly diagnosed hypertensive and pre-hypertensive participants $(n=217$ and 194, respectively). Risk of hypertension was significantly higher among older participants more than 40 years old $(\mathrm{OR}=1.71 ; 95 \% \mathrm{Cl}=$ 1.20 - 2.42), positive family history participants $(\mathrm{OR}=1.46 ; 95 \% \mathrm{Cl}=1.05-2.04)$, ever-smoked $(\mathrm{OR}=1.51 ; 95 \% \quad \mathrm{Cl}=1.10-$ 2.07) as compared to those who never smoked, duration of smoking more than 10 years $(\mathrm{OR}=1.78 ; 95 \% \mathrm{Cl}=1.24-2.54), \mathrm{BMI}$ of $25-29.9 \mathrm{~kg} / \mathrm{m}^{2}(\mathrm{OR}=3.14 ; 95 \% \mathrm{Cl}=2.00-$ 4.94) and $\mathrm{BMI} \geq 29.9 \mathrm{~kg} / \mathrm{m}^{2}(\mathrm{OR}=6.01 ; 95 \%$ $\mathrm{Cl}=3.75-9.67)$, abdominal circumference $\geq 102 \mathrm{~cm}(\mathrm{OR}=3.87 ; 95 \% \mathrm{Cl}=2.74-5.46)$ and diabetics $(\mathrm{OR}=2.80 ; 95 \% \mathrm{Cl}=1.63-$ 4.82) as compared to non-diabetics (Table 3). On the other hand, significant higher risk of 
pre-hypertension was associated only with obesity as measured by BMI $\geq 29.9 \mathrm{~kg} / \mathrm{m}^{2}$ $(\mathrm{OR}=1.87 ; 95 \% \quad \mathrm{Cl}=1.16-3.02)$ and abdominal circumference $\geq 102 \mathrm{~cm}(\mathrm{OR}=2.48$; $95 \% \mathrm{Cl}=1.71-3.60)($ Table 3$)$.

Multivariate logistic regression analysis showed that obesity as measured by body mass index, positive family history, ever smoking, and increased waist circumference were the significant predictors of workplace newly diagnosed hypertension among military active duty personnel (Table 4).

\section{DISCUSSION}

Although few national data exist about the prevalence of hypertension and associated risk factors among military personnel, none is known about pre-hypertension. This study provides community-based data on abnormal blood pressure among active duty Saudi military personnel.

Despite of the relatively young age and potential physical activity of participants, prevalence of hypertension (23.2\%) was approximately similar to that of the general population(5-7). Average of ten plus years of active duty in the military does not confer any long-term protection against overweight, obesity, or the associated comorbidities. This may reflect the impact of work-related factors to which those military personnel are exposed $^{(4)}$ in addition to other lifestyle determinants of the general population.

In the current study, obesity as measured by body mass index and waist circumference was the only significant predictor of pre-hypertension and it was significantly associated with newly diagnosed hypertension. This is in accordance with many other researches which recognized obesity as a major risk factor for the development of hypertension ${ }^{(1,11,12)}$. Saudi military is experiencing a trend toward increasing overweight that mirror the pattern among the general population ${ }^{(6-8)}$. Rise in overweight among the military is not explained by a decrease in physical activity(13). Overweight and obesity in the current study was $66.9 \%$ compared to similar figures reported among US military male personnel $\left(75 \%{ }^{(4)}\right.$ and $63 \%(14)$, respectively). A graded increase in 
the odds ratio was observed with increasing severity of overweight and obesity ${ }^{(14)}$ similar to the findings of the current study.

The addition of waist circumference (WC) to Body Mass Index (BMI) predicts a greater variance in health risk than does BMI alone ${ }^{(12,15)}$. Both WC and BMI were included in the same regression model. Waist circumference significantly predicts hypertension when used as a continuous variable. However, whether it is continuous or dichotomized as normal $(<102 \mathrm{~cm})$ or high $(\geq 102 \mathrm{~cm})$, BMI remains a significant predictor. Some researchers concluded that WC, and not BMI, explains obesity-related health risks $^{(15,16)}$. Others reported that WC was not predictive of the metabolic syndrome or component risk factors in $\operatorname{men}^{(12)}$, or suggested an equivalent value of both methods ${ }^{(17)}$.

Hypertension is common in diabetics and diabetes control is associated with prevention of cardiovascular complications ${ }^{(18,19)}$. Framingham study reported that $21 \%$ of patients with hypertension had high blood sugar ${ }^{(20)}$ compared to $12.9 \%$ in the current study.

Prevalence of smoking in the current study was considered very high. It is reported that $48.5 \%$ were either active or ex-smokers. Reports on smoking in the general population range from $10-20 \%$ among Saudi males( ${ }^{(6)}$. The high percentage of smoking in the current study significantly contributes to the increased prevalence of high blood pressure. However, further in-depth studies are highly recommended to investigate factors associated with smoking at the military workplace and its relation to the work pattern.

In the current study, positive family history, a known risk factor of hypertension, was reported in $35.9 \%$ of newly diagnosed cases compared to $23.6 \%$ among all hypertensives (including those with past history of hypertension). This supports the findings of the previous studies ${ }^{(7)}$, in contrary to Gan et al., (21) who reported that parental history of hypertension does not show significant correlation in the regression model. One limitation of this study is the impact of 
work pattern and job strain on the development of hypertension. Work pattern at the military services is unique. Soldiers spent 24 hours at the military units for long periods away from their families and homes. Living in the units is usually ascribed as tough and difficult. Place of work and work overload contribute significantly to job strain and consequently stress-related diseases(2,3,9). Such risks of workplace hypertension, should be considered in future studies.

While the prevalence of hypertension is low compared to older age groups, it remains important to detect cases early, as appropriate treatment may mitigate long-term cardiovascular risks and reduce target organ damage(21). Prevention and regular screening for hypertension and significant associated risk factors should be emphasized to improve readiness and reduce health care costs and disease burden among this active group ${ }^{(4)}$.

Pre-hypertension is common ${ }^{(1,2,9)}$ and it predicts the development of frank hypertension. Thus subjects with prehypertension should be closely followed(9).
Findings of the current study support the recommendation of lifestyle modification for pre-hypertensive patients ${ }^{(1,2)}$. However, further prospective studies are required to determine the role of pharmacotherapy in prehypertension.

Concerted efforts should be implemented to prevent and treat documented risk factors (mainly obesity and smoking) rather than just their associated comorbidities. These efforts are mainly the responsibility of the armed forces hospitals. These hospitals have a unique opportunity to respond to the epidemic of chronic diseases ${ }^{(4,22)}$, where comprehensive approach for workplace health promotion (e.g., weight management programs) can be effectively implemented $(3,23)$.

Moreover, there is an urgent need to motivate the physicians at the primary care level to identify the problem and implement requisite remedial measures focusing on lifestyle modification practices.

Acknowledgement: The investigators would like to express their great appreciation 
for the support of the Armed Forces Hospitals department) who assisted in data collection Administration as well as $\mathrm{M} \mathrm{Al-Asmary,} \mathrm{K} \mathrm{Al}$ - and measurements; and Merna (secretary of Amry, M Al-Malky, B Al-Ajmany and $\mathrm{T}$ Al- the Postgraduate Training and Research Khammash (nurses from family medicine Center) for data entry.

Table 1: Demographic characteristics of the studied personnel.

\begin{tabular}{|l|l|}
\hline Variables & Value \\
\hline Age in years, mean (SD); range & $34.20(7.02) ;(19-56 \mathrm{ys})$ \\
Marital status, $\mathrm{n}(\%)$ & $1080(87.20)$ \\
$\quad$ Married & $158(12.80)$ \\
Not married & \\
Education, $\mathrm{n}(\%)$ & $670(54.1)$ \\
$\quad$ Primary / intermediate & $489(39.5)$ \\
Secondary & $79(6.4)$ \\
University & \\
Smoking, $\mathrm{n}(\%)$ & $424(34.2)$ \\
Active smoker & $177(14.3)$ \\
Ex- smoker & $637(51.5)$ \\
Never smoked & $10.93(6.61)$ \\
Duration of smoking, mean $(\mathrm{SD}), \mathrm{ys}$ & \\
Obesity, $\mathrm{n}(\%)$ & $93(7.51)$ \\
Underweight $\left(<18.5 \mathrm{~kg} / \mathrm{m}^{2}\right)$ & $317(25.61)$ \\
Normal weight $\left(18.5-24.9 \mathrm{~kg} / \mathrm{m}^{2}\right)$ & $471(38.04)$ \\
Overweight $\left(25-29.9 \mathrm{~kg} / \mathrm{m}^{2}\right)$ & $357(28.84)$ \\
Obese $\left(30-34.9 \mathrm{~kg} / \mathrm{m}^{2}\right)$ & \\
Waist circumference, $\mathrm{n}(\%)$ & $922(74.5)$ \\
$<102 \mathrm{~cm}$ & \\
$\geq 102 \mathrm{~cm}$ & $(25.5)$ \\
\hline
\end{tabular}


Table 2: Prevalence of newly diagnosed and controlled hypertension in the studied participants.

\begin{tabular}{|c|c|c|c|}
\hline \multirow{2}{*}{} & \multicolumn{3}{|c|}{ Blood pressure as measured during screening } \\
\cline { 2 - 4 } & $\begin{array}{c}\text { Normal } \\
N(\%)\end{array}$ & $\begin{array}{c}\text { Pre-hypertension } \\
N(\%)\end{array}$ & $\begin{array}{c}\text { Hypertension } \\
N(\%)\end{array}$ \\
\hline Past history of hypertension & & & \\
Negative $(n=1168)$ & $757(64.8)$ & $194(16.6)$ & $217(18.6)$ \\
Positive $(n=70)$ & $30(42.9)$ & $20(28.6)$ & $20(28.6)$ \\
Total $(n=1238)$ & $787(63.6)$ & $214(17.3)$ & $237(19.1)$ \\
\hline
\end{tabular}

" Past history of medical diagnosis or treatment of hypertension.

Table 3: Univariate logistic regression analysis of independent variables associated with newly diagnosed pre-hypertension and hypertension.

\begin{tabular}{|c|c|c|c|c|c|}
\hline & \multicolumn{3}{|c|}{ Blood pressure } & \multirow{2}{*}{$\begin{array}{c}\text { Unadjusted OR } \\
(95 \% \mathrm{Cl}) \\
\text { Pre-hypertension } \\
\text { vs Normal }\end{array}$} & \multirow{2}{*}{$\begin{array}{l}\text { Unadjusted OR } \\
(95 \% \mathrm{Cl}) \\
\text { Hypertension vs } \\
\text { Normal }\end{array}$} \\
\hline & $\begin{array}{l}\text { Normal } \\
\mathrm{N}(\%)\end{array}$ & $\begin{array}{c}\text { Pre- } \\
\text { hypertens } \\
\text { ion } \\
\mathrm{N}(\%) \\
\end{array}$ & $\begin{array}{c}\text { Hypertensio } \\
n \\
N(\%)\end{array}$ & & \\
\hline \multicolumn{6}{|l|}{ Age } \\
\hline$<40$ ys & $600(67.0)$ & $146(16.3)$ & $150(16.7)$ & 1 & 1 \\
\hline$\geq 40$ ys & $157(57.7)$ & $48(17.6)$ & $67(24.6)$ & $1.26(0.85-1.85)$ & $1.71(1.20-2.42)$ \\
\hline \multicolumn{6}{|l|}{ Smoking } \\
\hline Never smoked & $410(67.8)$ & $100(16.5)$ & 95 (15.7) & 1 & 1 \\
\hline Ever smoked & $347(61.8)$ & $94(16.5)$ & $122(21.7)$ & $1.11(0.80-1.52)$ & $1.51(1.10-2.07)$ \\
\hline \multicolumn{6}{|l|}{ Duration of smoking } \\
\hline Never smoked & $410(67.8)$ & $100(16.5)$ & $95(15.7)$ & 1 & 1 \\
\hline$<10$ years & $155(65.4)$ & $39(16.5)$ & 43 (18.1) & $1.03(0.67-1.59)$ & $1.20(0.78-1.83)$ \\
\hline $\begin{array}{l}\geq 10 \text { ys } \\
\text { Eamilv }\end{array}$ & $192(58.9)$ & 55 (16.9) & 79 (24.2) & $1.17(0.80-1.73)$ & $1.78(1.24-2.54)$ \\
\hline Negative & 547 (67.0) & $130(15.9)$ & 139 (17.0) & 1 & 1 \\
\hline $\begin{array}{l}\text { Positive } \\
\text { Body Mass Index }\end{array}$ & $210(59.7)$ & $64(18.2)$ & $78(22.2)$ & $1.28(0.90-1.82)$ & $1.46(1.05-2.04)$ \\
\hline Normal & $237(76.5)$ & $42(13.5)$ & $31(10.0)$ & 1 & 1 \\
\hline Overweight & $298(68.0)$ & 67 (15.3) & $73(16.7)$ & $1.27(0.82-1.98)$ & $3.14(2.00-4.94)$ \\
\hline \multicolumn{5}{|l|}{ Waist Circumference } & $6.01(3.75-9.67)$ \\
\hline$<102 \mathrm{~cm}$ & 634 (71.3) & $131(14.7)$ & 124 (13.9) & 1 & 1 \\
\hline$\geq 102 \mathrm{~cm}$ & $123(44.1)$ & $63(22.6)$ & 93 (33.3) & $2.48(1.71-3.60)$ & $3.87(2.74-5.46)$ \\
\hline \multicolumn{6}{|l|}{ Diabetes Mellitus } \\
\hline Negative & 719 (66.2) & $178(16.4)$ & $189(17.4)$ & 1 & 1 \\
\hline Positive & $38(46.3)$ & $16(19.5)$ & $28(34.1)$ & $1.70(0.89-3.23)$ & $2.80(1.63-4.82)$ \\
\hline
\end{tabular}


Table 4: Multivariate logistic regression analysis of predictors of hypertension among the studied participants.

\begin{tabular}{|l|l|l|l|l|l|}
\hline Independent variables & B & SE & p- value & $\begin{array}{l}\text { Adjusted } \\
\text { OR }\end{array}$ & $95 \% \mathrm{Cl}$ \\
\hline Family history & 0.38 & 0.18 & 0.03 & 1.46 & $1.03-2.06^{*}$ \\
Smoking & 0.37 & 0.17 & 0.03 & 1.45 & $1.05-2.02^{*}$ \\
Overweight (BMI $\left.25-29.9 \mathrm{~kg} / \mathrm{m}^{2}\right)$ & 0.33 & 0.26 & 0.21 & 1.39 & $0.84-2.30$ \\
Obesity (BMI $\left.\geq 29.9 \mathrm{~kg} / \mathrm{m}^{2}\right)$ & 1.00 & 0.34 & 0.003 & 2.71 & $1.39-5.28^{*}$ \\
Waist circumference & 0.04 & 0.01 & 0.001 & 1.04 & $1.02-1.06^{*}$ \\
Diabetes Mellitus & 0.56 & 0.29 & 0.054 & 1.75 & $0.99-3.11$ \\
\hline
\end{tabular}

* statistically significant

Logistic regression model includes terms of family history (positive vs. negative), smoking (ever vs. never); overweight and obesity vs. normal weight; waist circumference as a continuous variable and diabetics (high blood sugar or past history of diagnosis and/or treatment) vs. non-diabetics.

\section{REFERENCES}

1. Israeli E, Schochat T, Korzets Z, Tekes-Manova D, Berheim J, Gola E. Pre-hypertension and obesity in adolescents: a population study. Am J Hypertens. 2006; 19 (7): 708-12.

2. Grotto I, Grossman E, Huerata M, Saharabi Y. Prevalence of prehypertension and associated cardiovascular risk profiles among young Israeli adults. Hypertension. 2006: 48 (2): 254-9.

3. Kress AM, Hartzel MC, Peterson MR. Burden of disease associated with overweight and obesity among U.S. military retirees and their dependents, aged 38-64, 2003. Prev Med. 2005; 41 (1): 63-9.

4. Nowichki EM, Billington CJ, Levive AS, Hoover $\mathrm{H}$, Must A, Naumova $\mathrm{E}$. Overweight, obesity, and associated disease burden in Veterans affairs ambulatorycare populations. Mil Med. 2003; 168 (3): 252-6.

5. Siddiqui S, Ogbeide DO, Karim A, AlKhalifa I. Prevalence of hypertension in patients attending Al-Kharj Military
Hospital. Saudi Med J. 2000; 21 (6): 558-60.

6. Al- Khashman AS. Screening for hypertension. Assessing the knowledge, attitudes and practice of primary health care in Riyadh, Saudi Arabia. Saudi Med J. 2001; 22 (12): 1096-100.

7. Abolfotooh MA, Abu-Zeif $\mathrm{HAH}$, Abdelaziz M, Alkija W, Mahfouz AA, Bassuni WA. Prevalence of hypertension in south-western Saudi Arabia. East Mediteran H J. 1996; 2 : 211-8.

8. Al-Sharif AL, Al-Khaldi YM. Resources availability for care of hypertensives at primary health settings in South western Saudi Arabia. Saudi Med J. 2003; 24 (5): 466-71.

9. Grossman A, Grossman C, Barenboim E, Azaria B, Goldstein L, Grossman E. Pre-hypertension as a predictor of hypertension in military aviators: A longitudinal study of 367 men. Aviat Space Environ Med. 2006; 77 (11):1162-5.

10. Harada K, Karube $\mathrm{Y}$, Saruhara $\mathrm{H}$, Takeda K, Kumajima I. Workplace hypertension is associated with obesity 
and family history of Hypertension. Hypertens Res. 2006; 29 (12): 969-76.

11. Janssen I, Katzmarzyh PT, Ross R. Body mass index, waist circumference, and health risk: evidence in support of current National Institutes of Health guidelines. Arch Intern Med. 2002; 14 (18): 2079-9.

12. Ardern $\mathrm{Cl}$, Katzmarzyk PT, Janssen I, Ross R. Discrimination of health risk by combined body mass index and waist circumference. Obes Res. 2003; 11 (1): $135-42$

13. Lindquist $\mathrm{CH}$, Bray RM. Trends in overweight and physical activity among U.S.Military personnel, 1995-1998. Prev Med. 2001; 32 (1): 57-665.

14. Must A, Spadano J. Coaklet EH, Field AE, Colditz G, Dietz WH. The disease burden associated with overweight and obesity. JAMA. 1999; 282 (16): 1523-9.

15. Jassen I, Katzmarzyk PT, Ross R. Waist circumference and not body mass index explains obesity-related health risk. Am J Clinic Nutr. 2004; 79 (3): 379-84.

16. Wildman RP, Gu D, Reynolds K, Duan $\mathrm{X}, \mathrm{Wu} \mathrm{X}, \mathrm{He} \mathrm{J}$. Are waist circumference and body mass index independently associated with cardiovascular disease risk in Chinese adults? Am J Clin Nutr. 2005; 82 (6): 1195-202.

17. Bosy-Westphal A, Geisler C, Onur S, Korth O, Selberg O, Schrezenmeir J, et al. Value of body fat mass vs. anthropometric obesity indices in the assessment of metabolic risk factors. Int J Obes. 2006; 30 (3): 475-83.
18. Tahtinen TM, Vanhala MJ, Oikarinen JA, Keinanen-Kiukaanniemi SM. Effect of smoking on the prevalence of insulin resistance-associated cardiovascular risk factors among Finnish men in military service. J Cardivasc. 1998; 5 (56): 319-23.

19. Raitakari OT, Porkka KV, Rasanen L, Viikari JS. Relations of life-style with lipids, blood pressure and insulin in adolescents and young adults. The cardiovascular risk in young Finns study. Athersclerosis. 1994; 111 (2): 237 -46 .

20. Kennel WB. Contribution of the Framingham study to prevention Cardiology. Bishop Lecture. J Amer Coll Cardiol. 1990; 15: 20611.

21. Gan SK, Loh CY, Seet B. Hypertension in young adults- an underestimated Problem. Singapore Med J. 2003; 44 (9): 448-52.

22. Das SR, Kinsinger LS, Yancy WS, Wang $A$, Ciesco $E$, Burdick $M$, et al. Obesity prevalence among veterans at Veterans Affairs medical facilities. Am J Prev Med. 2005; 28 (3): 291-4.

23. Krerss Am, Peterson MR, Hartzell MC. Association between obesity and depressive symptoms among U.S. Military active duty service personnel, 2002. J Psychosom Res. 2006; 60 (3): 2673-1. 